\title{
The Impact of Movie and TV Works on Songshan Mountain Tourism
}

\author{
yanlimin ${ }^{1, a}$ \\ ${ }^{1}$ University for Science \& Technology Zhengzhou, Zhengzhou 450064,China \\ a412660112@qq.com
}

Keywords: movie and TV tourism; Impact; Songshan Mountain

\begin{abstract}
Based on the current situation of Songshan Mountain movie and TV tourism, the paper analyzes how movie and TV works have a positive impact on Songshan Mountain tourism and mainly play a huge role in positively shaping the image for the tourism destination, effectively promoting the tourism destination, and enriching the content and form of the tourism products, and how movie and TV works have a negative impact on the local environment, and the image of the tourism destination and others.
\end{abstract}

As a form of cultural tourism, movie and TV tourism has cultural attributes such as entertainment, aesthetics, education, and physical and mental relaxation. In the process of integration with tourism products, movie and TV culture is an invisible tourism resource as the basic content of creative tourism culture. And tourism activity is a kind of existing form of movie and TV culture, so it is an extension of movie and TV service in the process of integration. The research on the movie and TV industry and tourism refers to the impact of movie and TV works on tourism.

\section{Current situation of Songshan movie and TV tourism}

Songshan Mountain tourism did not go smoothly. The tourism was in the initial stage from 1978 to 1982 . In 1982, Songshan scenic area was listed as one of the first national scenic spots by the State Council due to the film Shaolin Temple, and the number of tourists also began to grow rapidly, which meant that the traveling craze triggered by movie and TV works also began. After 24 years, Shaolin Temple appeared on TV due to 100 episodes of TV series Shaolin Temple Legend once again, and thus realized that media and spread had the crucial significance to restructuring its cultural image. Movie and TV works show the local customs and cultural customs; in the meantime, they bring the cultural connotation of the story into the tourist attractions to endow the original image of the scenic spot with a new sense. Movie and TV works, live performance and others continuously enriches the "Shaolin Kung Fu" brand of Songshan Mountain. Songshan, vigorously promoted through movie and TV works, have gained significant benefits.

\section{Positive impact of movie and TV works on Songshan Mountain tourism}

2.1 Shaping the positive image for the scenic area

Basically, the traditional ways to advertise the tourist area refer to leaflets, advertisement, and pamphlets. Compared with traditional ways such as advertisement or pamphlets, movie and TV works can break the limitations of time and cost, conduct propaganda in a coherent and comprehensive manner, and enable the tourists to repeat the resources of the tourist area in mind. In the case of the shaping of the scenic area, movie and TV plays select carefully and display the natural scenery, which is graceful or grand, or seemingly ordinary but factually extraordinary, screen and sort out the best natural scenery through shot and language for the audiences. The natural scenery in the movie and TV plays is unique and desirable due to the combination of fantasy 
and reality. In addition, movie and TV plays skillfully add the plot to conduct continuous natural and cultural propaganda for the tourist attractions, further enable people to discover the beauty of the tourist attractions virtually, and thus motivate the tourists to travel to the tourist attractions. So in essence, movie and TV tourism is a new way of marketing promotion for tourist destinations.

\subsection{Improving the visibility of the tourist area}

Shaolin Temple, located at the foot of Wuru Peak of Songshan Mountain, in Dengfeng city, Henan province, is the sub scenic spot of Songshan Mountain, the birthplace of Shaolin martial arts, and the home of Zen Buddhism of Chinese of Chinese Han Buddhism. It not only includes scenic spots such as Shaolin Monastery, Pagoda Forest, Dharma Cave, and Ancestor' s Monastery, but also has the Shaolin culture of Zen, Military, and Medicine with the history of 1000 years. In 1982, Shaolin Temple, known as the first temple in the world, was really famous overseas due to the hot film Shaolin Temple in the global. Shaolin Temple in Songshan Mountain received more and more visitors and got more and more benefits with each passing day, which gradually became stable. After being repeatedly promoted by a series of Kung Fu movies evolved from the movie Shaolin Temple and Kung Fu novels by Jin Yong, Shaolin Temple has been more famous in the world and become a cultural brand of Chinese Martial Arts. After that, Shaolin Temple appeared on TV due to 100 episodes of TV series Shaolin Temple Legend once again, and thus realized that media and spread had the crucial significance to restructuring its cultural image. Because of these movie and TV works, the concept that the global Kung Fu originates from Shaolin Temple goes deeply into the human mind. Since then, movie and TV works centered on Shaolin Kung Fu appear one after another.

\subsection{Promoting the local economy, martial arts, and culture}

The movie Shaolin Temple promoted tourism and martial arts in Dengfeng city. Shaolin Temple tourism greatly stimulated the local culture and economy, and powerfully promoted the whole industrial structure of Dengfeng culture. For example, in 1981, Shaolin Temple was bleak and desolate and had a dozen monks in total, including 9 old monks. All monks lived on 28 acres of barren farmlands. Before 1982, the villagers around Shaolin Temple only earned 30 Yuan per year, and the economic income of Dengfeng County was in a dozen places from bottom in the economic income of Henan province. Shaolin Temple was well known due to movie spread. The villagers around Shaolin Temple began to open shops and set up martial arts schools. Some family hotels and economic hotels began to flourish and drive the surrounding economy. Some villagers grew to be a guide and explained the local landscape and culture to the tourists. To a large extent, the local residents had jobs and got a higher income. Shaolin Temple in Songshan Mountain in Henan province famous for meditation and martial arts is an enterprise with diversified business now. It sets up an English website to advertise itself, performs from place to place, and builds sub temples around the world. It has become a large-scale international company with overseas annual income of up to ten million pounds. This year, the visitors at home and abroad made 9.58 million trips to Dengfeng city in total, and its ticket income reached 362 million Yuan and its tourism revenue reached about 6.2 billion Yuan.

\section{Negative impact of movie and TV works on Songshan Mountain tourism}

\subsection{Contrast between the image shaped by movie and TV works and the actual image}

The tourist destinations in movie and TV plays, shot and decorated carefully by photographers, art designers, and the professionals good at post production and others, enable people to enjoy 
beauty against the actual. Based on artistic embellishment, the kind of beauty is possibly unreal, in other words, the tourist destinations in movie and TV plays are more beautiful than the original tourist destinations. Affected by the movie with the same name as Shaolin, the visitors generally believe that the movie Shaolin Temple truly shows Shaolin Temple in Songshan Mountain. Attracted by the beautiful scenery and the plots in the movie, they visit Shaolin Temple in Songshan Mountain. When the visitors see the actual scenic spots, they find that the actual scenic spots fail to meet their original expectations. Movie and TV plays beautify them too much, so they feel disappointed at the actual ancient temple with bad service and undeserved temperament and quite different from the beautiful scenery of sunrise at Songshan cols, frightened birds due to morning bell, streams and brooks in forests, and green grasses on the slope. It is the disadvantages of movie and TV plays in the image shaping of scenic spots.

\subsection{Tourism image falls into custom Shaolin Temple Crisis}

Shaolin Temple became famous all over the world due to a movie 30 years ago. Shaolin Temple scenic spot also became the brightest one in scenic spots in Songshan Mountain. Under the shielding effect of Shaolin Temple, the scenic spots fell into the custom crisis. After the hot movie Shaolin Temple, many movie and TV works of the same style as Shaolin Temple were on one after another, and mostly promoted martial arts culture. And most of visitors did not know that Songshan scenic spots include eight major scenic spots such as Shaolin Temple, Songyang Academy, Zhongyue Temple, Luya Waterfall, and Sanhuang Village, and they are the key windows opening to the outside world for Zhengzhou and even the whole country. At present, the only Shaolin Temple scenic spot is developed particularly. Although other scenic spots have rich natural resources and very high cultural value, they have lower visibility due to weak publicity and the shielding effect of Shaolin Temple. The visitors think in a one-sided way that Shaolin Temple is a synonym for Songshan Mountain and represents the whole Songshan Mountain. In fact, Shaolin scenic spot is just a small part of Songshan cultural heritages, and constitutes the main part of Songshan scenic spots along with other resources. Other cultures and folk customs are limited due to custom effect. Because of the lack of the development of tourism products, another seven Songshan secondary scenic spots are completely ignored by the visitors and become the blocked scenic spots.

\subsection{Excessive commercial operation after the rapid increase in popularity}

After a hot movie Shaolin Temple, movie and TV works such as the Legend of Shaolin Temple and the Epic of Shaolin Kung Fu appeared one after another, became the universally well-known tourist products of high quality, and effectively enhanced the visibility and reputation of Shaolin Temple in Songshan Mountain. It is good to enhance the visibility of Shaolin Temple. But the monastery originally is a temple for God and Buddha and a sacred place for religious activities. Shaolin Temple has become a key window, by which Chinese culture attracts foreigners and China displays spirit of ancient Zen enlightenment, few desires, meditation, martial arts, and Zen and Kung Fu cultivating the mind due to publicity. But now Shaolin Temple is very worldly. The troupe consisting of warrior monks of Shaolin Temple has visited many countries and performed for more than one thousand times.

Excessive commercial operation results in secularization. Shaolin Temple scenic spots become more and more famous and increasingly flourish; however, they also put themselves into various condemnations, rapidly decline in social image, and are in more serious negative situation. The current Shaolin Temple subverts the fixed image in human mind, that is, people can be far away from the mortal world and live a sequestered life for meditation, loses its deserved mystery and 
sacred sense and its original appeal, and changes its cultural atmosphere in essence. To improve the bad image of the scenic spots is a matter of great urgency.

\section{References}

[1]Chen Xuejun. The Successful Elements of South Korean Movie and TV Tourism [N]. The ninth edition, January 12, 2007, China Travel Daily.

[2]Liu Binyi, Liu Qin. Current Situation and Trend of Chinese Movie and TV Tourism [J]. 2004,(19):77-81, Travel Journal.

[3]Pan Lili. The Analysis of the Impact of Movie and TV Shooting on Shooting Location Tourism

—Based on Xin Chang City, Zhejiang Province [J]. 2005,25(6):928-932, Economic Geography.

[4]Zhang Yang. Discussion about Deep Development of Chinese Movie and TV Tourism from the Perspective of Travel Boom due to South Korean TV Soaps [J]. 2006(9):80-86, Travel Edition, Journal of Beijing International Studies University.

[5]Tian Wupu, Ge Quansheng, Xi Jianchao, Liu Haolong. Research on Formation and Development Mechanism-Based on Qiao Family Courtyard, in Shanxi [J]. 2007(7): 52-57, Travel Journal

[6]Meng Ping. Large-scale Live Performance: Tourism and Cultural Feast. the 13th edition, July 11, 2005, China Travel Daily 